\title{
NUF2 as an anticancer therapeutic target and prognostic factor in breast cancer
}

\author{
SHANMEI LV, WENJIE XU, YANYAN ZHANG, JILING ZHANG and XUEJUN DONG \\ Department of Clinical Laboratory Center, Shaoxing People's Hospital (Shaoxing Hospital, \\ Zhejiang University School of Medicine), Shaoxing, Zhejiang 312000, P.R. China
}

Received July 18, 2020; Accepted October 9, 2020

DOI: 10.3892/ijo.2020.5141

\begin{abstract}
Breast cancer (BC) is the most frequently diagnosed type of cancer, and the leading cause of cancer-associated mortality in females worldwide. The aim of the present study was to investigate the prognostic and therapeutic potential of NUF2 in BC. The expression levels of NUF2 in $\mathrm{BC}$ tissues and cell lines were evaluated via bioinformatics, reverse transcription-quantitative PCR, western blot analysis and immunohistochemistry (IHC). In addition, the effect of NUF2 knockdown on BC cell proliferation and apoptosis was investigated using small interfering RNA (siRNA) technology. Bioinformatics and IHC analysis showed that NUF2 was overexpressed in BC tissues. Furthermore, western blot and RT-qPCR analyses demonstrated that NUF2 was upregulated in BC cells. In addition, BC cells transfected with NUF2 siRNA exhibited significantly decreased proliferation and colony formation, and increased apoptosis, compared with the control. Additionally, cell cycle analysis revealed that NUF2 induced G0/G1 cell cycle arrest by inhibiting cyclin B1 expression. Collectively, the present study suggested that NUF2 may represent a promising prognostic biomarker and a potential therapeutic target for BC.
\end{abstract}

\section{Introduction}

Breast cancer (BC) is the leading cause of cancer-associated mortality among females worldwide $(1,2)$. In total, 268,600 new cases of BC were diagnosed worldwide in 2019, whereas $\mathrm{BC}$ is the second leading cause of cancer-associated mortality (15\%) after lung cancer; the incidence of $\mathrm{BC}$ is increasing among Asian women, with an annual rate of $1.8 \%$ (3). Recently, the development of screening tools and effective treatment

Correspondence to: Professor Xuejun Dong, Department of Clinical Laboratory Center, Shaoxing People's Hospital (Shaoxing Hospital, Zhejiang University School of Medicine), 568 Zhongxing North Road, Shaoxing, Zhejiang 312000, P.R. China

E-mail: dxj9666@163.com

Key words: NUF2, therapeutic target, prognostic factor, breast cancer approaches have greatly improved the survival rate of patients with $\mathrm{BC}(4,5)$. The treatment of early $\mathrm{BC}$ involves complex combinations among the three main treatment modalities, namely surgery, systemic therapy and radiation therapy (6). Notably, the mortality rate of BC declined by $40 \%$ between 1989 and 2016; despite advances in early detection and treatment of BC, $20-30 \%$ of patients with early BC will develop recurrent disease and distant metastases $(3,7)$. Metastasis remains the leading cause of death in patients with $\mathrm{BC}(3,7)$. Molecular targeted therapeutic approaches have advanced current knowledge concerning disease pathogenesis and individualized treatment. For example, the monoclonal antibody trastuzumab, targeted against human epidermal growth factor receptor, has been shown to improve survival in patients with $\mathrm{BC}$ (8); however, the prognosis remains poor. Therefore, more personalized therapies with less adverse events are urgently required, further supporting the need for effective therapeutic targets and prognostic biomarkers.

NUF2, a core component of the Ndc80 kinetochore complex, also known as cell division cycle associated 1, was first identified as a centromere protein (9). It has been reported that NUF2 may interact with centromere-associated protein E (CENP-E) and contribute to stable spindle kinetochore-microtubule attachment $(10,11)$. NUF2 downregulation promotes kinetochore attachment defects and induces mitotic cell death (10). Notably, NUF2 serves an important role in regulating mitosis. NUF2 is upregulated in several types of cancer, including colon, gastric, ovarian and renal cell cancers (12-14). Furthermore, NUF2 overexpression is associated with poor prognosis in patients with non-small cell lung and colorectal cancers $(14,15)$. In colorectal and gastric cancer, it was reported that NUF2 knockdown attenuated tumor growth and significantly increased the sub- $\mathrm{G}_{1}$ fraction of the cell cycle (12). These reports supported the possible role of NUF2 in tumorigenesis.

The present study provided substantial evidence regarding the important role of NUF2 in the malignant potential and survival of $\mathrm{BC}$, and revealed a promising prognostic biomarker and a therapeutic target for $\mathrm{BC}$.

\section{Materials and methods}

Cell culture. The human mammary carcinoma cell lines MCF-7, MDA-MB-231, Hs578T and T47D, and the human 
breast epithelial cell line MCF10A were purchased from the Cell Bank of Chinese Academy of Sciences. MCF-7, MDA-MB-231, Hs578T and T47D cells were maintained in DMEM (HyClone; Cytiva) supplemented with $10 \%$ fetal bovine serum (FBS; Gibco; Thermo Fisher Scientific, Inc.). MCF10A cells were cultured in DMEM with Ham's F12 mixture (DMEM/F12) supplemented with $6 \%$ equine serum (Gibco; Thermo Fisher Scientific, Inc.), $10 \mu \mathrm{g} / \mathrm{ml}$ insulin, $0.5 \mathrm{mg} / \mathrm{ml}$ hydrocortisone (both Sigma Aldrich; Merck KGaA) and $1 \%$ penicillin-streptomycin (HyClone; Cytiva). All cell lines were maintained at $37^{\circ} \mathrm{C}$ in a humidified atmosphere with $5 \% \mathrm{CO}_{2}$.

Patients and tissue samples. BC tissues and corresponding adjacent normal tissues samples were obtained from 49 patients with BC (mean age, 54.65 \pm 12 years; range, 33-86 years) undergoing surgery at Shaoxing People's Hospital (Shaoxing, China) between December 2015 and April 2016 for immunohistochemistry (IHC). Clinical characteristics were retrospectively reviewed, and prognostic information was recorded on the basis of clinical follow-up visits or telephone (once every 6 months). The pathological stages of breast cancer patients were determined based on the 7th edition of the American Joint Committee on Cancer staging system (16). Patients who had received neoadjuvant chemotherapy or radiotherapy, or who had a history of other malignant tumors were excluded. The Ethics Committee of Shaoxing People's Hospital approved the present study, and written informed consent was obtained from all participants.

$I H C$. IHC was conducted using $3-\mu \mathrm{m}$ paraffin-embedded tissue sections. The tissue samples were fixed in $10 \%$ neutral formalin at room temperature for $24 \mathrm{~h}$. Briefly, the tissue sections were heated at $65^{\circ} \mathrm{C}$ for deparaffination, and at $121^{\circ} \mathrm{C}$ for $120 \mathrm{sec}$ in citrate buffer ( $\mathrm{pH}$ 6.0) for antigen retrieval. To block endogenous peroxidase activity, all sections were treated with $3 \%(\mathrm{v} / \mathrm{v})$ hydrogen peroxide at room temperature for 10 min. Following blocking with $10 \%$ goat serum (Beyotime Institute of Biotechnology) at $37^{\circ} \mathrm{C}$ for $30 \mathrm{~min}$, tissue sections were then incubated with an anti-NUF2 primary antibody (1:400; cat. no. ab122962; Abcam) at $37^{\circ} \mathrm{C}$ for $1 \mathrm{~h}$. Subsequently, the sections were incubated at $37^{\circ} \mathrm{C}$ for $30 \mathrm{~min}$ with HRP-conjugated polymer as a secondary antibody, stained with 3,3'-diaminobenzidine according to the instructions of the GTVision ${ }^{\mathrm{TM}}$ III Detection System/Mo Rb kit (GeneTech Biotechnology Co., Ltd.) and counterstained with hematoxylin at room temperature for 2-3 $\mathrm{min}$. The negative control sections were incubated with phosphate buffered saline (PBS) instead of the primary antibody. The immunostaining images were acquired using a light microscope (magnification, x100; Leica DM3000; Leica Microsystems GmbH). All sections were evaluated independently by two pathologists, who were blinded to the purpose of the study.

The immunohistochemical staining score was calculated by counting the percentage of positive cells in five randomly selected fields from each slide. The staining positive rate was defined as follows: $0,<25 \%$ positive cells; $1,25-50 \%$ positive cells; $2,50-75 \%$ positive cells and $3,75-100 \%$ positive cells In addition, staining intensity was scored as follows: 0 , no coloration; 1, light yellow; 2, yellow; and 3, brown. The two scores were combined to obtain the overall score: 0 , negative $(-)$; 1-2, weakly positive (+); 3-4, moderate positive (++); and 5-6, strongly positive $(+++)$.

Bioinformatics analysis. The expression levels of NUF2 in patients with BCs and normal controls were further compared using Gene Expression Profiling Interactive Analysis (GEPIA2; http://gepia2.cancer-pku.cn/\#index). GEPIA2 is an online database for analyzing the gene expression profiles of 9,736 tumors and 8,587 normal samples from The Cancer Genome Atlas (TCGA; https://cancergenome.nih.gov/) and the genotype-tissue expression programs (https://www. gtexportal.org/) (17). The Kaplan-Meier Plotter database (http://kmplot.com/analysis/) were used to perform survival curve and log-rank test analyses to identify the association between NUF2 expression and the prognosis of patients with BC. Patients were divided into high and low expression groups based on the median expression value.

Transfection. The small interfering RNA (siRNA) clone targeting human NUF2 gene (NM_031423; siNUF2) was purchased from Guangzhou RiboBio Co., Ltd. [siRNA-1, cat. no. siB1533140940; siRNA-2, cat. no. siB1533141009; siRNA-3, cat. no. siG151013041657; negative control siRNA (siNC), cat. no. siN05815122147]. siRNA-1 was selected as the siNUF2 for subsequent experiments after evaluating transfection efficiency. MCF-7 and MDA-MB-231 cells were seeded into 6 -well plates at a density of $2 \times 10^{5}$ cells/well prior to transfection, and when they reached the log growth phase and $60-70 \%$ confluence, cells were transfected with siNUF2 or siNC (50 nM) using Lipofection 6000 (Beyotime Institute of Biotechnology), according to the manufacturer's instructions. Following transfection for 24-48 h, the cells were washed with PBS and collected for reverse transcription-quantitative (RT-q)PCR and western blot analysis.

RT-qPCR analysis. Total RNA was extracted from MCF-7 and MDA-MB-231 cells using TRIzol ${ }^{\circledR}$ reagent (Invitrogen; Thermo Fisher Scientific, Inc.) and RT-qPCR was conducted with a One Step TB Green ${ }^{\mathrm{TM}}$ PrimeScript $^{\mathrm{TM}}$ RT-PCR kit II (Takara Bio, Inc.) according to the manufacturer's protocol: $42^{\circ} \mathrm{C}$ for $5 \mathrm{~min}$ and $95^{\circ} \mathrm{C}$ for $10 \mathrm{sec}$; followed by 40 cycles of $95^{\circ} \mathrm{C}$ for $5 \mathrm{sec}$ and $60^{\circ} \mathrm{C}$ for $20 \mathrm{sec}$; and finally $65^{\circ} \mathrm{C}$ for $15 \mathrm{sec}$. The mRNA expression levels were determined on a Roche LightCycler ${ }^{\circledR} 480$ instrument (Roche Diagnostics) using the following pairs of primers: NUF2 forward, 5'-TAC CATTCAGCAATTTAGTTACT-3' and reverse, 5'-TAGAAT ATCAGCAGTCTCAAAG-3'; and $\beta$-actin (internal control) forward, 5'-CATGTACGTTGCTATCCAGGC-3' and reverse, 5'-CTCCTTAATGTCACGCACGAT-3'. All experiments were performed in triplicate, and the mRNA expression levels of NUF2 were calculated using the $2^{-\Delta \Delta \mathrm{Cq}}$ method (18).

Western blot analysis. Total proteins isolated from MCF-7, MDA-MB-231, Hs578T, T47D and MCF10A cells were used for western blot analysis. Briefly, cultured cells were lysed with RIPA buffer (Beyotime Institute of Biotechnology) supplemented with $1 \mathrm{mM}$ PMSF and $0.25 \mathrm{U} / \mu 1 \mathrm{RNase}$, and the protein concentration was then determined using a BCA protein assay kit (Beyotime Institute of Biotechnology). 
Subsequently, equal quantities of proteins (25-30 $\mu \mathrm{g} / \mathrm{lane})$ were separated via 10\% SDS-PAGE, and were then transferred onto PVDF membranes (cat. no. IPVH00010; EMD Millipore). The membranes were blocked with 5\% skimmed milk at room temperature for $2 \mathrm{~h}$, and probed with anti-NUF2 (1:1,000; cat. no. ab180945; Abcam), $\beta$-actin $(1: 5,000$; cat. no. BS6007M; Bioworld Technology, Inc.), anti-Bax (1:1,000; cat. no. 2772; Cell Signaling Technology, Inc.), anti-Bcl-2 (1:1,000; cat. no. 4223; Cell Signaling Technology, Inc.) and anti-cyclin B1 (1:1,000; cat. no. ab7957; Abcam) antibodies at $4^{\circ} \mathrm{C}$ overnight. Membranes were then washed with TBS- $0.1 \%$ Tween 20 and incubated with the corresponding HRP-conjugated secondary goat anti-rabbit IgG antibody (1:5,000; cat. no. BS13278; Bioworld Technology, Inc.) at room temperature for $1 \mathrm{~h}$. Protein bands were detected with BeyoECL Plus Enhanced Chemiluminescence reagent (Beyotime Institute of Biotechnology) and analyzed on a LAS-4000 Science Imaging System (Fujifilm Holdings Corporation). Densitometry of protein bands was measured and analyzed with ImageJ software (v1.52a; National Institutes of Health).

Colony formation assay. For the colony formation assay, following siRNA transfection for $24 \mathrm{~h}, 10^{3}$ cells/well were seeded into a new 6-well plate, and cultured in $2 \mathrm{ml}$ DMEM supplemented with $10 \%$ FBS for 10 days or until colonies were visible to the naked eye. Colonies were then washed with PBS, fixed in $95 \%$ ethanol for 15 min at room temperature, and stained with $0.1 \%$ crystal violet for $15 \mathrm{~min}$ at room temperature. After being washed twice with PBS, colonies ( $>50$ cells/colony) were counted using ImageJ v1.52a software.

Cell proliferation assay. To evaluate the effect of NUF2 knockdown on $\mathrm{BC}$ cell proliferation, cell proliferation assays were conducted in both MCF-7 and MDA-MB-231 cell lines using a Cell Counting Kit-8 (CCK-8; Jiangsu Kaiji Bio-Technology Co., Ltd.) according to the manufacturer's instructions. Briefly, cells were seeded into 96-well plates at a density of $1 \times 10^{3}$ cells/well in quintuple and cultured at $37^{\circ} \mathrm{C}$ for $1,2,3$ or 4 days. Subsequently, $10 \mu$ l CCK- 8 reagent was added into each well, and cells were then incubated for an additional $1 \mathrm{~h}$. Cell proliferation was determined by measuring the absorbance at $450 \mathrm{~nm}$ using a microplate reader (Bio-Rad Laboratories, Inc.).

Cell cycle analysis. The cell cycle was evaluated in MCF-7 and MDA-MB-231 cells via flow cytometry following cell staining with propidium iodide (PI). Briefly, $24 \mathrm{~h}$ after siRNA transfection, MCF-7 and MDA-MB-231 cells ( $2 \times 10^{5} /$ well) were seeded into 6-well plates and incubated at $37^{\circ} \mathrm{C}$. Subsequently, cells were harvested and fixed in $75 \%(\mathrm{v} / \mathrm{v})$ ethanol overnight at $4^{\circ} \mathrm{C}$. Fixed cells were washed twice with ice cold PBS, resuspended in RNase A solution and incubated at $37^{\circ} \mathrm{C}$ for $30 \mathrm{~min}$. The cell suspension was then supplemented with PI and incubated at room temperature for $30 \mathrm{~min}$. The cell cycle was performed on a flow cytometer (FACS Calibur; BD Biosciences). Data were analyzed using ModFit LT 4.0 (Verity Software House).

Apoptosis analysis. Apoptosis was analyzed by flow cytometry. Briefly, MDA-MB-231 and MCF-7 cells were seeded into 6-well plates at a density of $2 \times 10^{5}$ cells/well. Following transfection with siRNA clones for $24 \mathrm{~h}$, cells were harvested, washed with ice-cold PBS and resuspended in 1X binding buffer. The apoptosis rate was quantitatively determined by detecting phosphatidylserine on apoptotic cells using an Annexin V/PI double-staining apoptosis assay kit (cat. no. KGA511; Nanjing KeyGen Biotech Co., Ltd.) according to the manufacturer's instructions. Cells were incubated with Annexin V and PI for $30 \mathrm{~min}$, and analyzed with a flow cytometer (FACS Calibur; BD Biosciences) and ModFit software. The apoptotic rate was calculated as the sum of the percentage of early and late apoptotic cells. All experiments were performed in triplicate.

Statistical analysis. Statistical analyses were performed with SPSS 23.0 (IBM Corp.) and GraphPad Prism 7 software (GraphPad Software, Inc.). All experiments were performed in triplicate. The IHC results with respect to patient characteristics were analyzed using Fisher's exact test, while comparisons of IHC scores between two paired groups were performed by Wilcoxon signed-rank test. Bioinformatics comparison of expression in patients and controls was performed using Student's t-test. Comparisons between three or more groups were performed by one-way ANOVA followed by Dunnett's post hoc test. Univariate and multivariate analyses of clinical indicators of cancer-associated mortality were conducted using the Cox proportional hazard model. $\mathrm{P}<0.05$ was considered to indicate a statistically significant difference.

\section{Results}

NUF2 is associated with poor prognosis in BC. The expression of NUF2 was detected in 49 BC tissue specimens via IHC. Furthermore, its expression pattern was classified in tissues based on staining from negative, to weakly, moderately and strongly positive (Fig. 1). Positive staining was observed in $43 / 49$ BC cases (87.8\%), including 29 cases $(59.2 \%)$ with strongly positive staining and 14 cases $(28.6 \%)$ with weakly or moderately positive staining, in addition to 6 cases (12.2\%) negative for NUF2 staining (Table I). Subsequently, the association between NUF2 expression and clinical characteristics was assessed. The number of distant metastasis in patients with $\mathrm{BC}$ was too small to adequately perform association analysis. For those variables that could be analyzed, it was determined that NUF2 was significantly associated with estrogen receptor (ER) status only ( $\mathrm{P}=0.042$; Table I). Furthermore, univariate analysis was performed to evaluate the association between prognosis and other factors, including age ( $\geq 53$ vs. $<53$ years), lymph node stage $(\mathrm{N} 1+\mathrm{N} 2$ vs. N0), tumor stage (T3+T4 vs. $\mathrm{T} 1+\mathrm{T} 2)$ and NUF2 expression status (strong vs. weak/absent). Among these parameters, strong NUF2 expression $(\mathrm{P}=0.0334)$ and advanced age $(\mathrm{P}=0.0456)$ were significantly associated with a less favorable prognosis. In multivariate analysis, strong NUF2 expression $(\mathrm{P}=0.0183)$ and advanced age $(\mathrm{P}=0.0263)$ were identified as independent prognostic factors (Table II).

NUF2 is highly expressed in BC tissues and cell lines. The NUF2 expression data from 1,085 patients with BC were analyzed using the GEPIA2 database. The results indicated that NUF2 was upregulated in patients with BC (Fig. 2A). Kaplan-Meier plotter database analysis revealed that increased 
Table I. Association between NUF2 expression and clinical characteristics of patients with breast cancer $(n=49)$.

\begin{tabular}{|c|c|c|c|c|c|}
\hline \multirow[b]{2}{*}{ Characteristic } & \multirow[b]{2}{*}{ Number } & \multicolumn{3}{|c|}{ NUF2 expression } & \multirow[b]{2}{*}{ P-value } \\
\hline & & - & $+/++$ & +++ & \\
\hline \multicolumn{6}{|l|}{ Age, years } \\
\hline$<53$ & 24 & 3 & 7 & 14 & \multirow[t]{2}{*}{0.993} \\
\hline$\geq 53$ & 25 & 3 & 7 & 15 & \\
\hline \multicolumn{6}{|l|}{ Tumor size, $\mathrm{cm}$} \\
\hline$<2$ & 10 & 1 & 2 & 7 & \multirow[t]{2}{*}{0.732} \\
\hline$\geq 2$ & 39 & 5 & 12 & 22 & \\
\hline \multicolumn{6}{|l|}{ TNM stage } \\
\hline I & 13 & 0 & 3 & 10 & \multirow[t]{3}{*}{0.095} \\
\hline II & 24 & 4 & 10 & 10 & \\
\hline III & 12 & 2 & 1 & 9 & \\
\hline \multicolumn{6}{|l|}{ ER status } \\
\hline Positive & 37 & 4 & 14 & 19 & \multirow[t]{2}{*}{0.042} \\
\hline Negative & 12 & 2 & 0 & 10 & \\
\hline \multicolumn{6}{|l|}{ PR status } \\
\hline Positive & 30 & 3 & 11 & 16 & \multirow[t]{2}{*}{0.281} \\
\hline Negative & 19 & 3 & 3 & 13 & \\
\hline \multicolumn{6}{|l|}{ HER2 status } \\
\hline Positive & 47 & 6 & 13 & 28 & \multirow[t]{2}{*}{0.733} \\
\hline Negative & 2 & 0 & 1 & 1 & \\
\hline \multicolumn{6}{|c|}{ Lymph node metastasis } \\
\hline Yes & 25 & 4 & 6 & 15 & \multirow[t]{2}{*}{0.617} \\
\hline No & 24 & 2 & 8 & 14 & \\
\hline \multicolumn{6}{|l|}{ Tumor stage } \\
\hline $\mathrm{T} 1$ & 23 & 3 & 4 & 16 & \multirow[t]{4}{*}{0.483} \\
\hline $\mathrm{T} 2$ & 19 & 3 & 8 & 8 & \\
\hline $\mathrm{T} 3$ & 2 & 0 & 1 & 1 & \\
\hline $\mathrm{T} 4$ & 5 & 0 & 1 & 4 & \\
\hline \multicolumn{6}{|c|}{ Lymph node stage } \\
\hline No & 25 & 2 & 7 & 16 & \multirow[t]{4}{*}{0.536} \\
\hline $\mathrm{N} 1$ & 13 & 2 & 5 & 6 & \\
\hline N2 & 5 & 0 & 1 & 4 & \\
\hline N3 & 6 & 2 & 1 & 3 & \\
\hline
\end{tabular}

ER, estrogen receptor; HER2, human epidermal growth factor receptor; PR, progesterone receptor.

expression of NUF2 in patients with BC was closely associated with a poor prognosis (Fig. 2B). Additionally, IHC results revealed that NUF2 was upregulated in tumor tissues compared with adjacent normal tissues (Fig. 2C). Consistently, the mRNA and protein expression levels of NUF2 were increased in BC cell lines compared with non-tumorigenic epithelial MCF-10A cells, as demonstrated by RT-qPCR and western blot analysis, respectively (Fig. 2D and E). These findings indicated that NUF2 was significantly upregulated in BC tissues and cell lines. Among different BC cell lines, MCF-7 and MDA-MB-231 cells exhibited relatively higher NUF2 expression; therefore, these cell lines were considered suitable for subsequent loss-of-function experiments.
NUF2 knockdown in BC cells using siRNA. To evaluate the effects of NUF2 in BC cells, MCF-7 and MDA-MB-231 cells were transfected with siNUF2 to silence its expression. As shown in Fig. 3, compared with the siNC group, the protein and mRNA expression levels of NUF2 were significantly decreased following siNUF2 transfection in both MDA-MB-231 and MCF-7 cells. Based on the transfection efficiencies of different siNUF2 sequences, siRNA-1 was selected for subsequent experiments.

Knockdown of NUF2 inhibits BC cell proliferation and colony formation. To investigate the biological effect of NUF2 in BC cell growth, a CCK-8 assay over a 4-day period was conducted 
Table II. Cox proportional hazards model analysis of prognostic factors in patients with breast cancer.

\begin{tabular}{lclll}
\hline Variable & Hazard ratio & 95\% CI & Unfavorable/favorable & \\
\hline Univariate analysis & & & \\
NUF2 expression & 5.144 & $1.137-23.271$ & strong/weak, absent \\
Age, years & 8.738 & $1.043-73.203$ & $\geq 53 /<53$ & $0.0334^{\mathrm{a}}$ \\
Tumor stage & 0.239 & $0.053-1.085$ & $\mathrm{~T} 3+\mathrm{T} 4 / \mathrm{T} 1+\mathrm{T} 2$ & $0.0456^{\mathrm{a}}$ \\
Lymph node stage & 0.400 & $0.089-1.793$ & $\mathrm{~N} 1+\mathrm{N} 2 / \mathrm{N} 0$ & 0.0637 \\
Multivariate analysis & & & $\geq 53 /<53$ \\
Age, years & 0.074 & $0.008-0.736$ & strong/weak, absent \\
NUF2 expression & 8.412 & $1.434-49.357$ & $0.0263^{\mathrm{a}}$ \\
\hline
\end{tabular}

${ }^{a} \mathrm{P}<0.05$. CI, confidence interval.

A

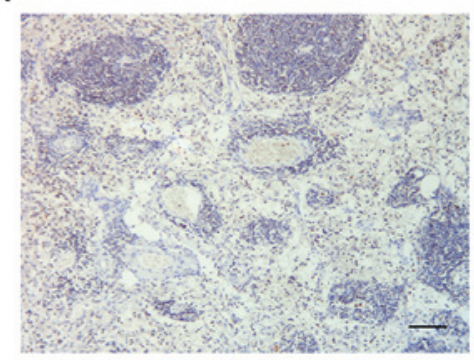

B

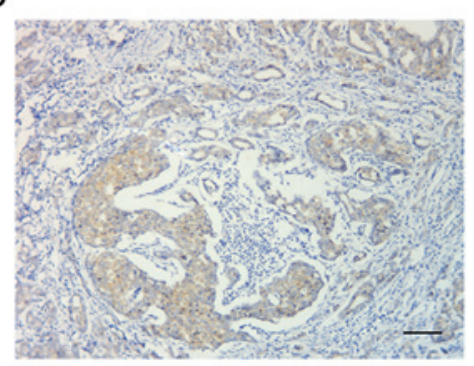

C

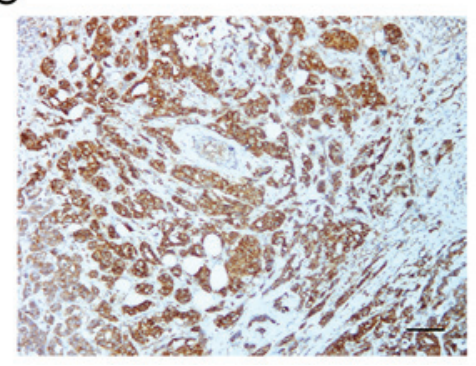

Figure 1. Immunohistochemistry analysis of NUF2 expression in human BC tissues. (A) NUF2-negative normal adjacent tissues. (B) Weak NUF2 expression in BC tissues. (C) Strong NUF2 expression in BC tissues. Magnification, x100; scale bar, $200 \mu \mathrm{m}$. BC, breast cancer.

A

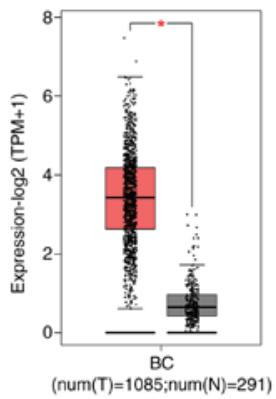

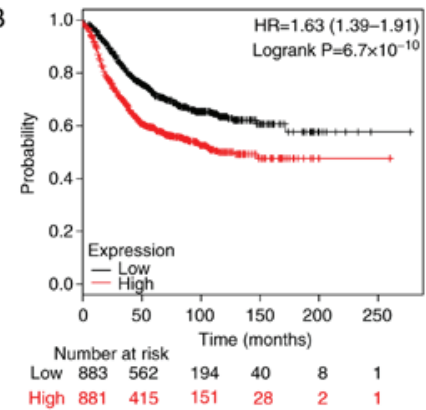

$E$
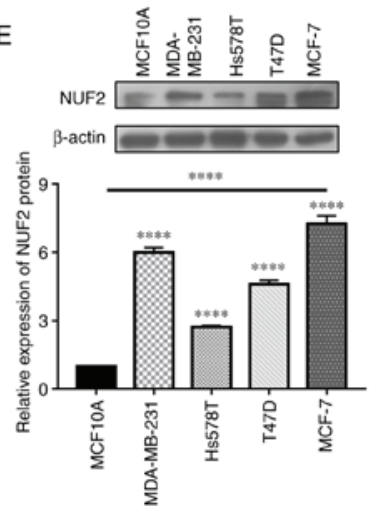

Figure 2. NUF2 is upregulated in BC tissues and cell lines, and is associated with poor prognosis. (A) Box plots of NUF2 transcripts in tumor and adjuvant normal tissues. (B) Kaplan-Meier analysis of the overall survival of patients with BC according to the expression levels of NUF2. The HR and 95\% confidence interval are included. (C) IHC analysis revealed that NUF2 was upregulated in BC tissues. (D) Reverse transcription-quantitative PCR and (E) western blot analyses of NUF2 expression in BC cells. Relative NUF2 expression levels in BC cells were normalized to $\beta$-actin and NUF2 expression in MCF-10A cells. Data are presented as the mean $\pm \mathrm{SD}$ of three independent repeats. ${ }^{*} \mathrm{P}<0.05,{ }^{* *} \mathrm{P}<0.01,{ }^{* * * * *} \mathrm{P}<0.0001 \mathrm{vs}$. MCF10A or as indicated; lines above multiple groups indicate the significance of the result of the one-way ANOVA. BC, breast cancer; HR, hazard ratio; IHC, immunohistochemistry; N, normal; T, tumor; TPM, transcripts per kilobase million. 
A

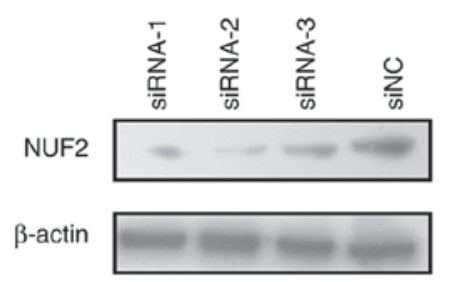

C

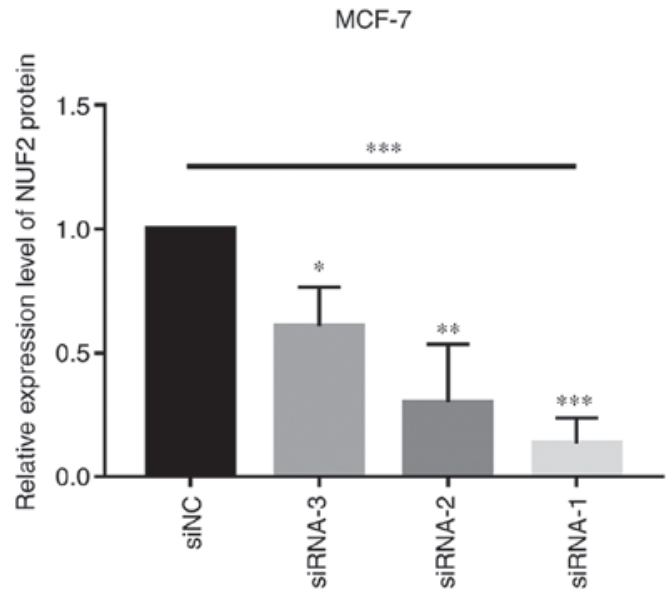

E

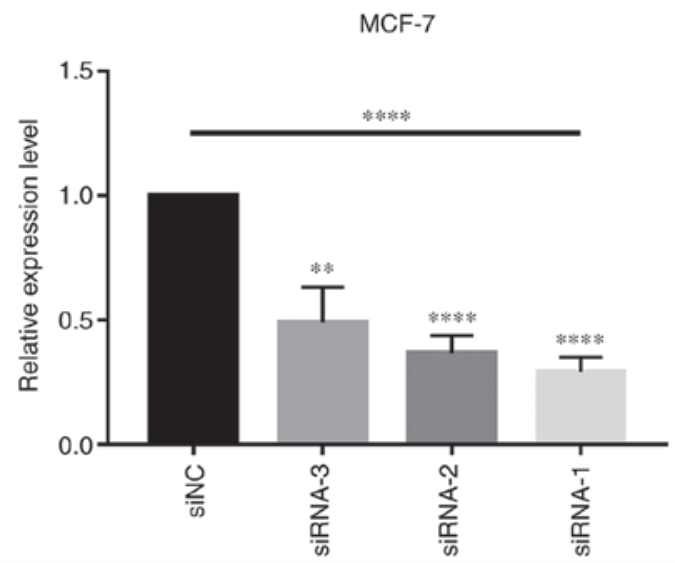

B

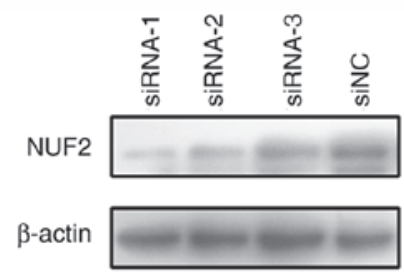

D
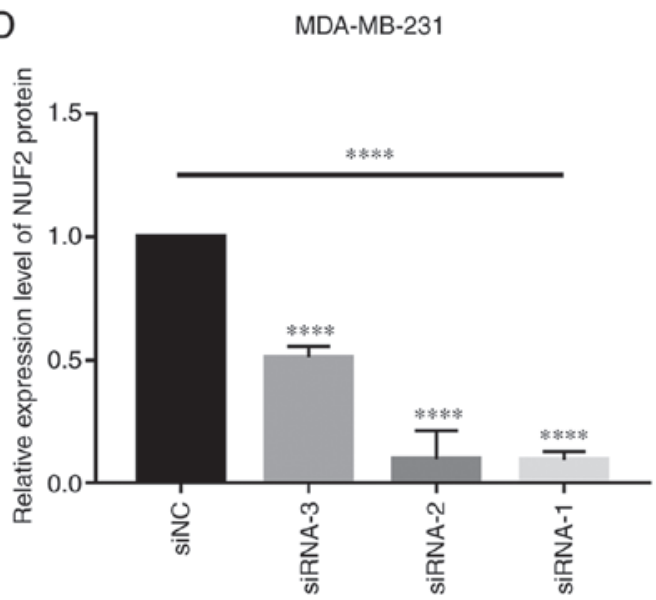

$\mathrm{F}$

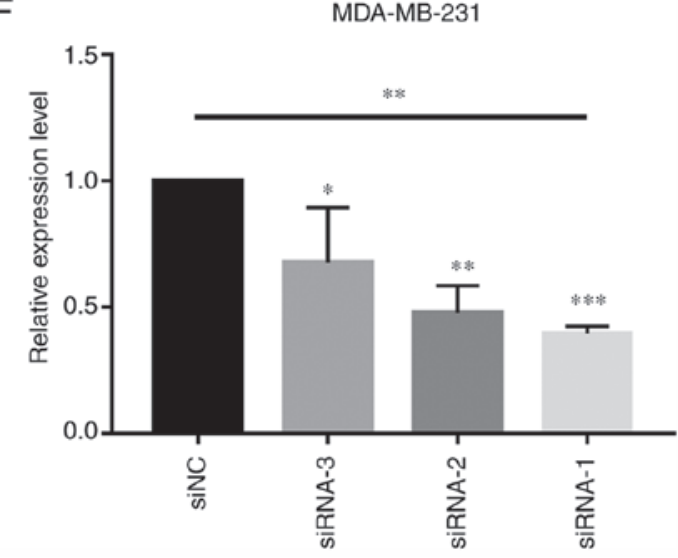

Figure 3. Knockdown efficiency of siNUF2 in breast cancer cells. Western blot analysis showing siRNA-mediated NUF2 downregulation in (A) MCF-7 and (B) MDA-MB-231 cell lines. Quantification of NUF2 protein expression after siRNA transfection in (C) MCF-7 and (D) MDA-MB-231 cells. mRNA expression levels of NUF2 were decreased in (E) MCF-7 and (F) MDA-MB-231 cells following transfection with siNUF2. Data are presented as the mean \pm SD of at least three independent experiments. ${ }^{*} \mathrm{P}<0.05,{ }^{* * *} \mathrm{P}<0.01,{ }^{* * *} \mathrm{P}<0.001,{ }^{* * * *} \mathrm{P}<0.0001 \mathrm{vs}$. siNC or as indicated; lines above multiple groups indicate the significance of the result of the one-way ANOVA. NC, negative control; siRNA, small interfering RNA.

in MDA-MB-231 and MCF-7 cells. NUF2 knockdown significantly attenuated MDA-MB-231 cell proliferation compared with siNC-transfected cells on days 3 and 4 (Fig. 4A). Similarly, NUF2 knockdown inhibited the proliferation of MCF-7 cells on days 3 and 4 (Fig. 4B). These results suggested that knockdown of NUF2 could potently suppress BC cell proliferation. Furthermore, the effect of NUF2 expression on long-term cell proliferation capacity was evaluated using a colony formation assay. The results revealed that colony formation ability was affected in MDA-MB-231 and MCF-7 cells following siRNA-mediated NUF2 knockdown. As presented in Fig. 4C and D, the number of colonies in the siNUF2 group was significantly reduced compared with the siNC group. These findings indicated that silencing of NUF2 expression served an important role in inhibiting $\mathrm{BC}$ cell growth.
Suppression of NUF2 induces cell cycle arrest and downregulates the expression of cell cycle regulators. NUF2 is a key mediator of kinetochore-microtubule attachment (9); therefore, NUF2 knockdown-mediated inhibition of BC cell proliferation may occur due to impediment of cell cycle progression or enhanced apoptosis. Therefore, to evaluate the mechanisms underlying the effect of NUF2 knockdown on cell cycle progression, the cell cycle distribution of both MCF-7 and MDA-MB-231 cells was evaluated via flow cytometry, and the percentage of cells in each phase of the cell cycle was determined. Compared with the siNC group, cell cycle progression was inhibited in the siNUF2 group, as determined based on the significant increase in the percentage of MCF-7 and MDA-MB-231 cells in G0/G1 phase (Fig. 5). Furthermore, the protein expression levels of the cell cycle-associated 
A

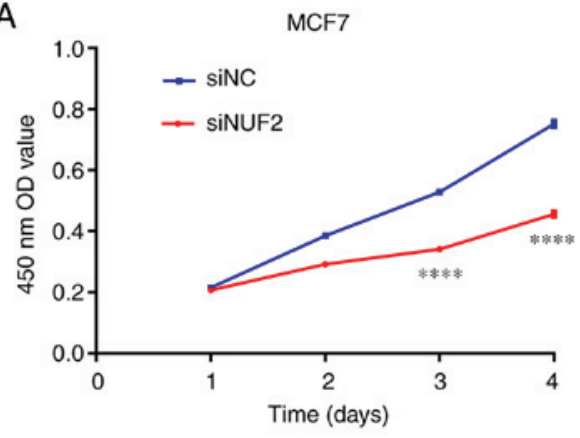

C

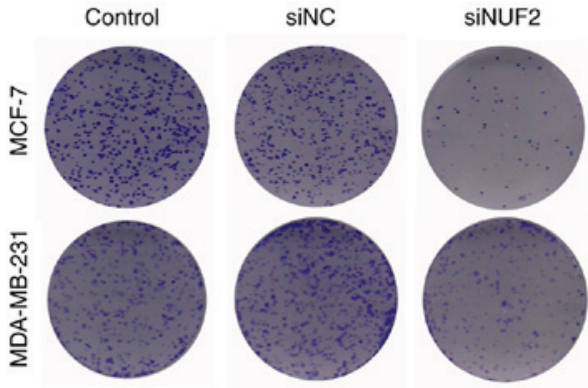

B

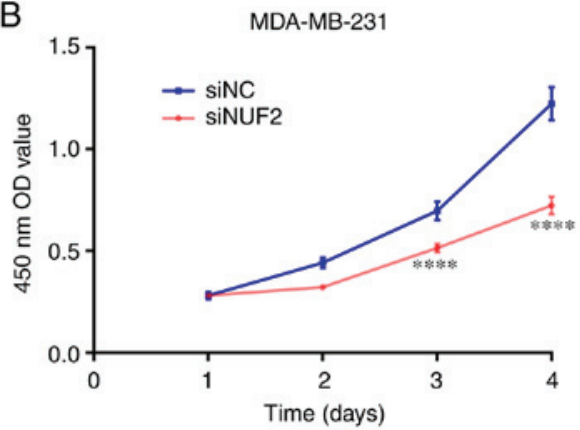

D

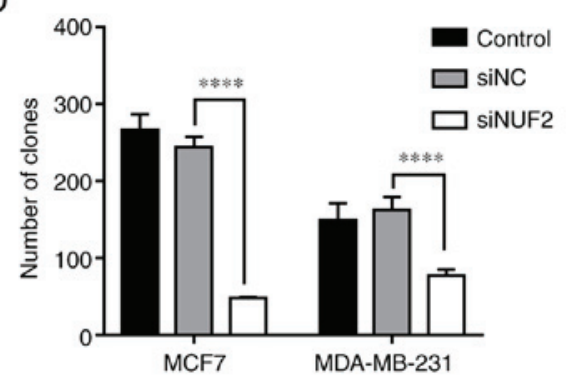

Figure 4. NUF2 affects BC cell proliferation. Cell Counting Kit-8 assay showing decreased proliferation of (A) MCF-7 and (B) MDA-MB-231 BC cells following NUF2 knockdown. (C) Colony formation assay showing decreased colony formation ability of MCF-7 and MDA-MB-231 cells following NUF2 knockdown. (D) Quantification of the colony formation assay results. Data are presented as the mean $\pm \mathrm{SD}$ of three independent repeats. ${ }^{* * * *} \mathrm{P}<0.0001 \mathrm{vs}$. siNC or as indicated. BC, breast cancer; NC, negative control; OD, optical density; siRNA, small interfering RNA.
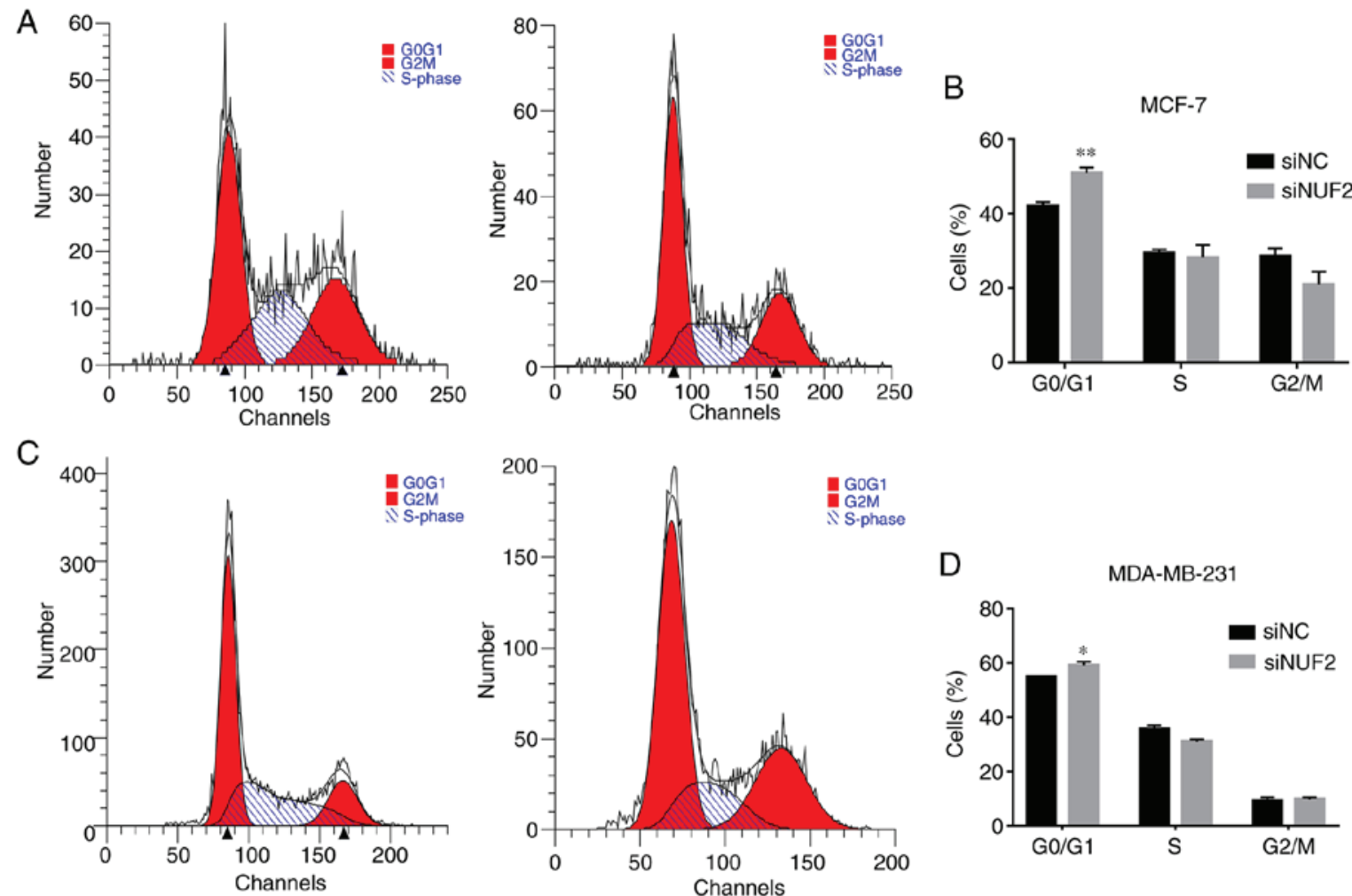

Figure 5. Effect of NUF2 knockdown on cell cycle progression in BC cells. (A) Flow cytometric analysis of cell cycle distribution and (B) quantitative analysis in MCF-7 BC cells transfected with siNUF2 or siNC. (C) Flow cytometric analysis of cell cycle distribution and (D) quantitative analysis in MDA-MB-231 BC cells transfected with siNUF2 or siNC. Percentages of cells in the G0/G1, $\mathrm{S}$ and $\mathrm{G}_{2} / \mathrm{M}$ phases of the cell cycle are presented. Data are presented as the mean $\pm \mathrm{SD}$ of three independent repeats. ${ }^{*} \mathrm{P}<0.05$. ${ }^{* *} \mathrm{P}<0.01$ vs. siNC. $\mathrm{BC}$, breast cancer; NC, negative control; siRNA, small interfering RNA.

protein cyclin B1 were decreased following NUF2 knockdown (Fig. 6). These results suggested that NUF2 knockdown mediated cell cycle arrest at the G0/G1 phase via cyclin B1 downregulation. 
A
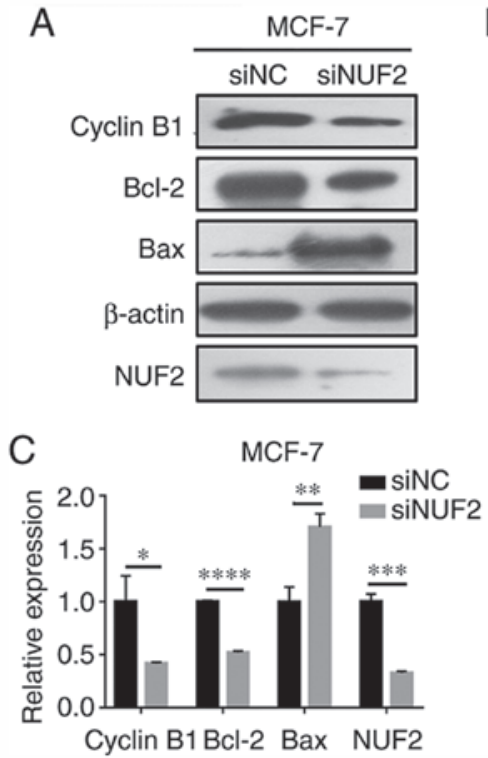

B
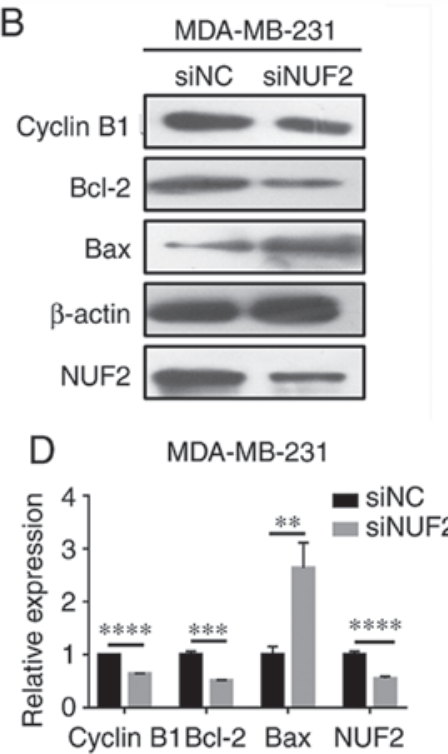

Figure 6. NUF2 knockdown affects the expression of cell cycle-associated proteins and apoptosis regulators in BC cells. Western blot analysis of cyclin B1, Bcl-2, Bax and $\beta$-actin expression in (A) MCF-7 and (B) MDA-MB-231 BC cells following NUF2 knockdown. Quantified expression of proteins in (C) MCF-7 and (D) MDA-MB-231 cells. Data are presented as the mean $\pm \mathrm{SD}$ of three independent repeats. ${ }^{*} \mathrm{P}<0.05,{ }^{* *} \mathrm{P}<0.01,{ }^{* * *} \mathrm{P}<0.001,{ }^{* * * * *} \mathrm{P}<0.0001$. BC, breast cancer; $\mathrm{NC}$, negative control; siRNA, small interfering RNA.
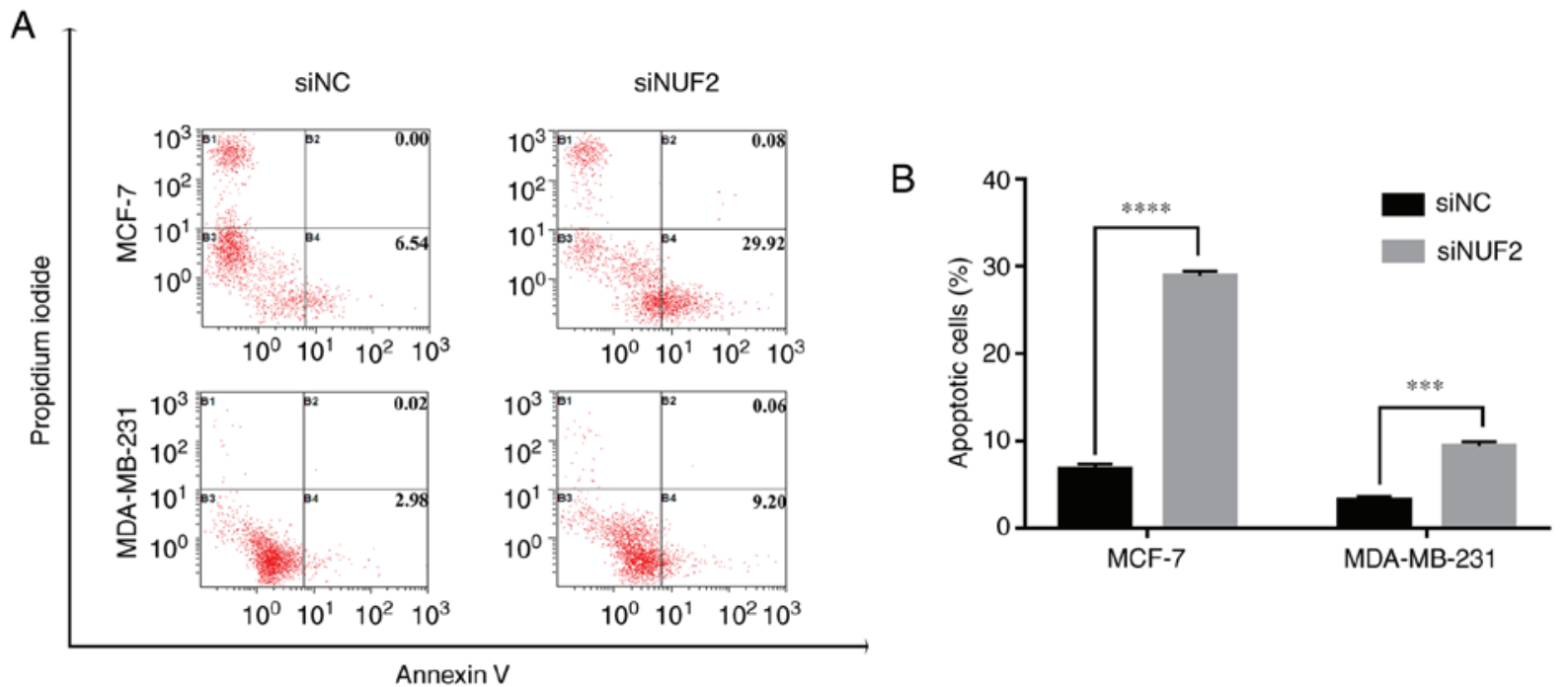

Figure 7. NUF2 knockdown promotes apoptosis in BC cells. (A) Flow cytometric analysis of apoptosis in MCF-7 and MDA-MB-231 BC cells transfected with siNUF2 or siNC. Cells were stained with Annexin V and propidium iodide, and analyzed via flow cytometry. (B) Percentage of apoptotic cells calculated from the corresponding quadrant. Data are presented as the mean $\pm \mathrm{SD}$ of three independent repeats. ${ }^{* * * *} \mathrm{P}<0.001,{ }^{* * * * *} \mathrm{P}<0.0001$. BC, breast cancer; $\mathrm{NC}$, negative control; siRNA, small interfering RNA.

NUF2 knockdown attenuates BC cell apoptosis. Cell apoptosis was examined by flow cytometry using Annexin V/PI double staining. Following NUF2 silencing, the results revealed a significant increase in the apoptotic rate of MCF-7 cells (Fig. 7). Similarly, the apoptotic rate was significantly increased in MDA-MB-231 cells in the siNUF2 group compared with the siNC group (Fig. 7). In addition, the expression levels of the apoptosis-associated proteins Bax and Bcl-2 were significantly upregulated and downregulated, respectively, in BC cells transfected with siNUF2 compared with siNC (Fig. 6). These findings indicated that NUF2 knockdown exerted a pro-apoptotic effect on $\mathrm{BC}$ cells.

\section{Discussion}

In the Ndc80-NUF2 complex, NUF2 is required to maintain the integrity of the centromere and the stability of the microtubule-binding site in the outer plate of the centromere (19). It has been reported that the Ndc80-NUF2 complex is involved in the development of several types of human cancer, including hepatocellular, lung, prostate and oral carcinomas (20-23). Although marked progress has been achieved in molecular targeted therapy for BC in the previous few years, current anticancer agents are characterized by limited efficacy and drug resistance (8). Therefore, the development of novel therapeutic 
targets to improve the clinical outcome of patients with $\mathrm{BC}$ is urgently required.

In the present study, IHC analysis revealed that NUF2 was upregulated in $\mathrm{BC}$ tissues compared with normal adjacent tissues (43/49 BC cases). This finding was consistent with results obtained from the GEPIA2 database analysis. Furthermore, Kaplan-Meier and Cox proportional hazard model analysis demonstrated that NUF2 overexpression was associated with a poor prognosis in patients with $\mathrm{BC}$. NUF2 was also upregulated in BC cell lines. These data supported the role of NUF2 as a prognostic biomarker for $\mathrm{BC}$. To further investigate the biological effect of NUF2 in BC cells, MDA-MB-231 and MCF-7 cells were transfected with siNUF2 to silence NUF2 expression. NUF2 downregulation significantly attenuated $\mathrm{BC}$ cell growth by inhibiting cell proliferation and colony formation ability, and induced apoptosis in BC cells. However, in the present study, the upregulation of NUF2 was not associated with tumor size. It is proposed that the number of patients enrolled in the study may have been too small to observe such an association, or there may have been inaccuracies in tumor size measurement, amongst other possible factors.

In addition, NUF2 silencing affected the expression levels of apoptosis- and cell cycle-associated proteins, including Bax, Bcl-2 and cyclin B1, in BC cells. Cyclin B1 serves an important role in the initiation of mitosis, and inhibition of cyclin B1 may result in cell cycle blockage and eventually apoptosis (24). In the present study, cell cycle analysis showed that the percentage of cells in G0/G1 phase was significantly increased following NUF2 knockdown, which was accompanied with decreased cyclin B1 expression levels. These results indicated that cell cycle blockage was associated with decreased cell proliferation and increased apoptosis.

NUF2 is a highly conversed component of the mitotic cycle complex, which serves an important role in maintaining spindle microtubule-kinetochore attachment (25). Decreased NUF2 expression inhibits the attachment of the kinetochore to the spindle microtubules, resulting in abnormal chromosome segregation, which in turn results in mitotic arrest and cell death $(10,11,26)$. In the early stages of mitosis, kinetic particles are attached to spindle microtubules to form a stable complex; however, impaired binding of kinetic particles to microtubules leads to complex instability and shortened complex half-life, eventually resulting in abnormal cell division and cell death $(10,11)$. Consistent with the these observations, NUF2 knockdown in $\mathrm{BC}$ cells resulted in reduced cell proliferation and increased apoptosis.

The present study had certain limitations, such as the absence of NUF2 overexpression experiments. Another potential limitation is that the specific underlying molecular mechanisms of NUF2-promoted cell proliferation were not revealed. Furthermore, the association between NUF2 expression in patients with $\mathrm{BC}$ and clinicopathological characteristics such as distant metastasis requires a greater number of patients. Further follow-up studies are required to more rigorously address these issues.

In conclusion, the present study demonstrated that NUF2 may serve an important role in the development and progression of BC, thus providing a potential target for molecular targeted therapy against BC.

\section{Acknowledgements}

Not applicable.

\section{Funding}

The present study was supported by the Public Technology Research Project of Zhejiang Province (grant no. LGF18H200006) and the Medicines Health Technology Plan Project of Zhejiang Province (grant no. 2018PY073).

\section{Availability of data and materials}

The datasets used and/or analyzed during the current study are available from the corresponding author on reasonable request.

\section{Authors' contributions}

SL, WX and XD were involved in the study design. SL and WX contributed to data collection and analysis. SL, JZ and YZ performed the RT-qPCR experiments and analyzed the data. All authors were involved in drafting the manuscript. XD critically reviewed the manuscript and provided final approval of the published version. All authors read and approved the final manuscript.

\section{Ethics approval and consent to participate}

The present study was approved and supervised by the Ethics Committee of Shaoxing People's Hospital. Written informed consent was obtained from all participants.

\section{Patient consent for publication}

Consent for publication was obtained from all participants.

\section{Competing interests}

The authors declare that they have no competing interests.

\section{References}

1. Torre LA, Siegel RL, Ward EM and Jemal A: Global cancer incidence and mortality rates and Trends-an update. Cancer Epidemiol Biomarkers Prev 25: 16-27, 2016.

2. Siegel RK, Miller KD and Jemal A: Cancer statistics, 2020. CA Cancer J Clin 70: 7-30, 2020.

3. Siegel R, Miller KD and Jemal A: Cancer statistics, 2019. CA Cancer J Clin 69: 7-34, 2019.

4. Miller KD, Nogueira L, Mariotto AB, Rowland JH, Yabroff KR, Alfano CM, Jemal A, Kramer JL and Siegel RL: Cancer treatment and survivorship statistics, 2019. CA Cancer J Clin 69: 363-385, 2019.

5. Bray F, Ferlay J, Soerjomataram I, Siegel RL, Torre LA and Jemal A: Global cancer statistics 2018: GLOBOCAN estimates of incidence and mortality worldwide for 36 cancers in 185 countries. CA Cancer J Clin 68: 394-424, 2018

6. Arnaout A, Lee J, Gelmon K, Poirier B, Lu FI, Akra M, Boileau JF, Tonkin K, Li H, Illman C, et al: Neoadjuvant therapy for breast cancer: Updates and proceedings from the seventh annual meeting of the canadian consortium for locally advanced breast cancer. Curr Oncol 25: e490-e498, 2018.

7. Kennecke H, Yerushalmi R, Woods R, Cheang MC, Voduc D, Speers CH, Nielsen TO and Gelmon K: Metastatic behavior of breast cancer subtypes. J Clin Oncol 28: 3271-3277, 2010. 
8. Sandoo A, Kitas GD and Carmichael AR: Breast cancer therapy and cardiovascular risk: Focus on trastuzumab. Vasc Health Risk Manag 11: 223-228, 2015

9. Nabetani A, Koujin T, Tsutsumi C, Haraguchi T and Hiraoka Y: A conserved protein, Nuf2, is implicated in connecting the centromere to the spindle during chromosome segregation: A link between the kinetochore function and the spindle checkpoint Chromosoma 110: 322-334, 2001.

10. DeLuca JG, Moree B, Hickey JM, Kilmartin JV and Salmon ED: hNuf2 inhibition blocks stable kinetochore-microtubule attachment and induces mitotic cell death in HeLa cells. J Cell Biol 159: 549-555, 2002.

11. Liu D, Ding X, Du J, Cai X, Huang Y, Ward T, Shaw A, Yang Y, Hu R, Jin C and Yao X: Human NUF2 interacts with centromere-associated protein $\mathrm{E}$ and is essential for a stable spindle microtubule-kinetochore attachment. J Biol Chem 282: 21415-21424, 2007.

12. Kaneko N, Miura K, Gu Z, Karasawa H, Ohnuma S, Sasaki H, Tsukamoto N, Yokoyama S, Yamamura A, Nagase H, et al: siRNA-mediated knockdown against CDCA1 and KNTC2, both frequently overexpressed in colorectal and gastric cancers, suppresses cell proliferation and induces apoptosis. Biochem Biophys Res Commun 390: 1235-1240, 2009.

13. Sethi G, Pathak HB, Zhang H, Zhou Y, Einarson MB, Vathipadiekal V, Gunewardena S, Birrer MJ and Godwin AK: An RNA interference lethality screen of the human druggable genome to identify molecular vulnerabilities in epithelial ovarian cancer. PLoS One 7: e47086, 2012.

14. Hayama S, Daigo Y, Kato T, Ishikawa N, Yamabuki T, Miyamoto M, Ito T, Tsuchiya E, Kondo S and Nakamura Y: Activation of CDCA1-KNTC2, members of centromere protein complex, involved in pulmonary carcinogenesis. Cancer Res 66: 10339-10348, 2006.

15. Kobayashi Y, Takano A, Miyagi Y, Tsuchiya E, Sonoda H, Shimizu T, Okabe H, Tani T, Fujiyama Y and Daigo Y: Cell division cycle-associated protein 1 overexpression is essential for the malignant potential of colorectal cancers. Int J Oncol 44: 69-77, 2014.

16. Edge SB, Byrd DR, Compton CC, Fritz AG, Greene FL and Trotti A III: AJCC cancer staging manual. 7th edition. Springer, pp237, 2009.
17. Tang Z, Li C, Kang B, Gao G, Li C and Zhang Z: GEPIA: A web server for cancer and normal gene expression profiling and interactive analyses. Nuclc Acids Res 45: W98-W102, 2017.

18. Livak KJ and Schmittgen TD: Analysis of relative gene expression data using real-time quantitative PCR and the 2(-Delta Delta C(T)) method. Methods 25: 402-408, 2001.

19. Wigge PA and Kilmartin JV: The Ndc80p complex from Saccharomyces cerevisiae contains conserved centromere components and has a function in chromosome segregation. J Cell Biol 152: 349-360, 2001.

20. Wang Y, Tan PY, Handoko YA, Sekar K, Shi M, Xie C, Jiang XD, Dong QZ, Goh BKP, Ooi LL, et al: NUF2 is a valuable prognostic biomarker to predict early recurrence of hepatocellular carcinoma after surgical resection. Int J Cancer 145: 662-670, 2019.

21. Yuan W, Xie S, Wang M, Pan S, Huang X, Xiong M, Xiao RJ, Xiong J, Zhang QP and Shao L: Bioinformatic analysis of prognostic value of ZW10 interacting protein in lung cancer. Onco Targets Ther 11: 1683-1695, 2018.

22. Obara W, Sato F, Takeda K, Kato R, Kato Y, Kanehira M, Takata R, Mimata H, Sugai T, Nakamura Y and Fujioka T: Phase I clinical trial of cell division associated 1 (CDCA1) peptide vaccination for castration resistant prostate cancer. Cancer Sci 108: 1452-1457, 2017.

23. Thang PM, Takano A, Yoshitake Y, Shinohara M, Murakami Y and Daigo Y: Cell division cycle associated 1 as a novel prognostic biomarker and therapeutic target for oral cancer. Int J Oncol 49: 1385-1393, 2016.

24. Menon VR, Peterson EJ, Valerie K, Farrell NP and Povirk LF: Ligand modulation of a dinuclear platinum compound leads to mechanistic differences in cell cycle progression and arrest. Biochem Pharmacol 86: 1708-1720, 2013.

25. Sundin LJ, Guimaraes GJ and Deluca JG: The NDC80 complex proteins Nuf2 and Hecl make distinct contributions to kinetochore-microtubule attachment in mitosis. Mol Biol Cell 22: 759-768, 2011.

26. DeLuca JG, Howell BJ, Canman JC, Hickey JM, Fang G and Salmon ED: Nuf2 and $\mathrm{Hecl}$ are required for retention of the checkpoint proteins Mad1 and Mad2 to kinetochores. Curr Biol 13: 2103-2109, 2003. 